\title{
MANAJEMEN PENANGGULANGAN GIZI PASCA BENCANA
}

\author{
Nur Rahma Batalipu ${ }^{1}$, Sudirman ${ }^{2}$, Ahmad Yani ${ }^{2}$ \\ ${ }^{1}$ Mahasiswa Fakultas Kesehatan Masyarakat, Unismuh Palu \\ ${ }^{2}$ Dosen Fakultas Kesehatan Masyarakat, Unismuh Palu
}

\begin{abstract}
Abstrack
Bencana merupakan kejadian luar biasa yang terjadi diluar kendali manusia. Besarnya dampak bencana yang mungkin terjadi membuat pentingannya perhatian seluruh masyarakat untuk kesiapsiap-siagaan dalam menghadapi bencana. Indonesia merupakan salah satu negara yang sangat rawan dengan bencana alam. Potensi bencana tersebut yaitu gempa bumi, tsunami, banjir, tanah longsor, kekeringan, kebakaran hutan dan lahan, gunung api, dan masih banyak lagi. Pada wilayah bencana, kebutuhan layanan kesehatan dan pangan akan meninggkat. Untuk itu penanggulangan bencana terkhusus untuk pemenuhan status gizi penyintas bencana perlu menjadi perhatian dan prioritas dalam manajemen penanggulangan bencana. Terpenuhnya asupan gizi penyintas bencana diharapkan mampu mencegah terjadinya bencana selanjutnya seperti wabah penyakit akibat penurunan status gizi para penyintas bencana. Makalah ini dibuat dengan mengumulkan beberapa artikel dan literatur terkait manajemen bencana dan penanggulangan gizi pasca bencana. Kegiatan penanganan gizi pada kedaruratan meliputi pelayanan gizi, penyuluhan gizi, penyediaan tenaga khusus atau sumber daya manusia dibidang gizi, dan penyediaan makanan. Tujuan umum dari kegiatan ini yaitu meningkatkan, menjaga dan mencegah memburuknya status gizi para penyintas bencana. Sementara tujuan khususnya yaitu memantau perkembangan status gizi para penyintas bencana. Makalah ini menyimpulkan bahwa penanggulangan gizi pasca bencana sangatlah penting untuk menjadi perhatian semua pihak yang bersangkutan. Penanggulangan gizi pasca bencana diharapkan mampu meningkatkan dan menjaga status gizi para penyintas bencana agar tidak terjadi masalah-masalah kesehatan lainnya yang tidak diinginkan.
\end{abstract}

\section{Kata kunci : Penanggulangan Bencana, Gizi dalam kedaruratan}




\section{PENDAHULUAN}

Bencana merupakan kejadian luar biasa yang terjadi diluar kendali manusia. Tanpa diketahui waktu terjadinya dan seberapa besar dampak kerugian yang akan ditimbulkan. Dampak bencana dapat berupa rusaknya lingkungan dan menyebabkan kematian masal. Besarnya dampak tersebut membuat pentingannya perhatian seluruh masyarakat untuk kesiapsiap-siagaan dalam menghadapi bencana (Sinaga, 2015).

Julukan sebagai negara dengan laboratorium bencana sudah melekat bahkan tidak asing lagi terdengar untuk negara Indonesia. Mengingat Indonesia merupakan salah satu negara yang sangat rawan dengan bencana alam. Bukan hanya dikenal rawan bencana, bencana alam yang sering melanda Indonesia bahkan beberapa tidak pernah terjadi atau baru pertama kalinya terjadi di Indonesia. Potensi bencana tersebut yaitu gempa bumi, tsunami, banjir, tanah longsor, kekeringan, kebakaran hutan dan lahan, gunung api, dan masih banyak lagi (Oktari, 2019).

Yang hingga kini masih sering diperbincangkan yaitu bencana likuefaksi. Likuefaksi atau peristiwa pencairan tanah, terjadi belum lama ini di Indonesia tepatnya di Kota Palu, Sulawesi Tengah. Likuefaksi adalah fenomena yang terjadi ketika tanah yang jenuh kehilangan kekuatan akibat adanya getaran secara mendadak, sehingga tanah yang padat dapat berubah wujud menjadi cair.

Tidak hanya bencana alam, Indonesia juga sering dilanda bencana nonalam seperti konflik sosial. Letak geografis, kondisi demografis serta keragaman sosio-kultural masyarakat Indonesia menjadi salah satu potensi terjadinya gesekan yang mengakibatkan terjadianya konflik sosial. Secara fisik bencana-bencana tersebut tentu berdampak pada rusaknya saran dan prasarana, pemukiman, juga fasilitas umum lainnya termasuk fasilitas kesehatan. Hal ini membuka peluang munculnya bencana baru seperti KLB penyakit tertentu. Masalah yang sering kali luput dari perhatian ialah kecukupan gizi bagi penyintas bencana. Penurunan status gizi pasca bencana dapat terjadi akibat layanan kesehatan terbatas, terputusnya jalur distribusi makanan serta sanitasi yang buruk (Kementrian Kesehatan RI, 2016)

Kebutuhan layanan kesehatan dan pangan jelas akan meninggkat pada daerah pasca bencana. Untuk itu manajemen penanggulangan terkhusus untuk pemenuhan status gizi penyintas bencana, perlu menjadi perhatian semua pihak. Khususnya kebutuhan nutrisi bayi, balita, anak-anak, ibu hamil serta lansia yang rentan terserang penyakit pasca bencana terjadi (Tumenggung, 2018). 
METODE

Makalah ini dibuat dengan mengumulkan beberapa artikel dan literatur terkait manajemen bencana dan penanggulangan gizi pasca bencana.

\section{HASIL DAN PEMBAHASAN}

Temuan pada makalah ini menunjukan bahwa masalah mendasar yang selalu terjadi pasca bencana yaitu penurunan status gizi masyarakat diwilayah bencana. Sayangnya dalam manajemen penanggulangan bencana, kurang adanya perhatian terhadap masalah gizi dalam kedaruratan. Penurunan status gizi masyarakat penyintas bencana dapat menyebabkan munculnya masalahmasalah kesehatan lainnya seprti diare, yang bisa mengamcam nyawa para penyintas bencana. Keterbatasan fasilitas kesehatan, kondisi pengungsian yang tidak layak, sanitasi yang buruk juga dapat menjadi pemicu memburuknya derajat kesehatan penyintas bencana (Suryani, 2017)

Penanganan gizi dalam kedaruratan bencana sangat penting. Beberapa hal yang menjadi penyebab pentingnya penanganan gizi yaitu keterbatasana dipengungsian, bantuan makanan untuk mempertahankan status gizi, perlu adanya survailens gizi untuk optimalisasi bantuan dan penanganan gizi yang sesuai (Salmayati, Hermansyah and Agussabti, 2016).
Kegiatan dalam penanganan gizi pada kedaruratan meliputi beberapa kegiatan yaitu pelayanan gizi, penyuluhan gizi, tenaga khusus atau sumber daya manusia dibidang gizi, dan penyediaan makanan (Salmayati, Hermansyah and Agussabti, 2016).

Tujuan umum dari kegiatan ini yaitu meningkatkan, menjaga dan mencegah memburuknya status gizi para penyintas bencana. Sementara tujuan khususnya yaitu memantau perkembangan status gizi para penyintas bencana (Kementerian Kesehatan RI, 2015)

Pelayanan gizi dilakukan oleh tenaga gizi yang ditempatkan khusus dilokasi pengungsian penyintas bencana untuk menyiapkan makanan darurat. Karena pada saat ditetapkan untuk menggungsi, para penyintas tidak mungkin menyiapkan makanannya sendiri (Salmayati, Hermansyah and Agussabti, 2016)

Selanjutnya kegiatan penyuluhan gizi bertujuan untuk merubah perilaku dan membangun mental penyintas untuk dapat mempertahankan dan meningkatkan status gizinya. Kegiatan ini diharakan mampu memberikan pemahaman terhadap penyintas akan pentingnya makanan bergizi meski dalam masa darurat bencana.

Dalam kedaruratan pasca bencana juga perlu adanya tenaga khusus dibidang gizi yang diperbantukan untuk dapur-dapur 
umum yang menyediakan makanan bagi para penyintas. Para tenaga gizi diharapkan dapat memberikan perhatian terhadap kebersihan dan menu makanan yang akan diberikan bagi para penyintas. Yang perlu diperhatikan juga pasca bencana, penyediaan bahan makanan harus dalam waktu yang sesingkat mungkin untuk memenuhi kebutuhan gizi para penyintas (Salmayati, Hermansyah and Agussabti, 2016)

\section{KESIMPULAN}

Makalah ini menyimpulkan bahwa penanggulangan gizi pasca bencana sangatlah penting untuk menjadi perhatian semua pihak yang bersangkutan. Penanggulangan gizi pasca bencana diharapkan mampu meningkatkan dan menjaga status gizi para penyintas bencana agar tidak terjadi masalah-masalah kesehatan lainnya yang tidak diinginkan.

\section{DAFTAR PUSTAKA}

Kementerian Kesehatan RI (2015)

Pedoman Kegiatan Gizi dalam

Penanggulangan Bencana.

Oktari, R. S. (2019) 'Peningkatan

Kapasitas Desa Tangguh Bencana', Jurnal Pengabdian kepada

Masyarakat (Indonesian Journal of

Community Engagement), 4(2), pp.

189-197.
Penanggulangan Krisis Kesehatan

Akibat Bencana.

Salmayati, S., Hermansyah, H. and Agussabti, A. (2016) 'Kajian penanganan gizi balita pada kondisi kedaruratan bencana banjir di kecamatan sampoiniet kabupaten aceh jaya', Jurnal Kedokteran Syiah Kuala, 16(3), pp. 176-180.

Sinaga, N. S. (2015) 'Peran Petugas

Kesehatan Dalam Manajamen Penanganan Bencana Alam', Jurnal ilmiah “INTEGRITAS” Vol, 1(1).

Suryani, A. S. (2017) 'Pemenuhan

Kebutuhan Dasara Bidang Kesehatan Lingkungan Bagi Penyintas Bencana Studi di Provinsi Riau dan Jawa Tengah'.

Tumenggung, I. (2018) 'Masalah Gizi dan Penyakit Menular Pasca Bencana', Journal Health And Nutritions, 3(1), pp. 1-9.

RI, K. K. (2016) Pedoman Teknis 